\title{
Joint Pain Undergoes a Transition in Accordance with Signal Changes of Bones Detected by MRI in Hip Osteoarthritis
}

\author{
Mikio Kamimura $^{1}$, Yukio Nakamura ${ }^{*, 2,3}$, Shota Ikegami ${ }^{2}$, Shigeharu Uchiyama ${ }^{2}$ and Hiroyuki Kato ${ }^{2}$ \\ ${ }^{1}$ Center of Osteoporosis and Spinal Disorders: Kamimura Orthopaedic Clinic, Matsumoto 399-0021, Japan \\ ${ }^{2}$ Department of Orthopaedic Surgery, Shinshu University School of Medicine, Asahi 3-1-1, Matsumoto 390-8621, Japan \\ ${ }^{3}$ Department of Orthopaedic Surgery, Showa Inan General Hospital, Komagane 399-4117, Japan
}

\begin{abstract}
Objectives: In this study, we aimed to investigate whether joint pain is derived from cartilage or bone alterations.

Methods: We reviewed 23 hip joints of 21 patients with primary hip osteoarthritis (OA), which were classified into Kellgren-Laurence (KL) grading I to IV. Plain radiographs and magnetic resonance imaging (MRI) were obtained from all of the 23 joints. Two of the 21 patients had bilateral hip OA. Pain was assessed based on the pain scale of Denis. A Welch $t$ test was performed for age, height, weight, body mass index, bone mineral density, and a Mann-Whitney $U$ test was performed for KL grading.

Results: Four of 8 hip joints with pain and OA showed broad signal changes detected by MRI. Fourteen hip joints without pain, but with OA did not show broad signal changes by MRI. Collectively, MRI analyses showed that broad signal changes in OA cases without joint pain or with a slight degree of joint pain were not observed, while broad signal changes were observed in OA cases with deteriorated joint pain.

Conclusion: Our findings suggest that hip joint pain might be associated with bone signal alterations in the hips of OA patients.
\end{abstract}

Keywords: Hip OA, MRI, signal changes, joint pain.

\section{INTRODUCTION}

Osteoarthritis (OA), the most common musculoskeletal disorder, is complex and multifaceted [1]. Previous studies have demonstrated that continuous mechanical stress causes articular cartilage degradation, which leads to bone degeneration in primary as well as secondary OA [2]. Therefore, in general it is considered that mechanical stress is the main cause of OA. Three decades ago, Radin and Rose proposed that $\mathrm{OA}$ could be initiated and progress from subchondral bones [3]. Burr and Gallant have reviewed that the main pathophysiology of $\mathrm{OA}$ is bone remodeling in subchondral bone [4]. Recently, OA is considered to be a whole-joint disease process that involves multiple tissues in and around the joint [5]. However, it is still challenging to predict the condition of OA in conjunction with joint pain.

We have currently reported that bone alterations could lead to primary hip OA. In that study, it was found that signal changes of bone by magnetic resonance imaging (MRI) were detected in the patients with joint pain, but

*Address correspondence to this author at the Department of Orthopaedic Surgery, Shinshu University School of Medicine, Asahi3-1-1, Matsumoto 390-8621, Japan; Tel: +81-263-37-2659; Fax: +81-263-35-8844;

E-mail: yxn14@aol.jp without advanced radiographic OA features. OA progressed as seen by plain radiographs in those cases within a few months after onset. Based on that study, we propose that such repeated physiological bone changes cause a portion of OA [unpublished data].

Recently, it has become possible to perform whole-organ semiquantitative assessment of OA using MRI [5,6]. As far as we know, there is no report on MRI findings in conjunction with hip joint pain transition in hip OA patients.

The aim of our study was to examine the relationship between signal changes of bone detected by MRI and joint pain in hip OA patients.

\section{PATIENTS AND METHODS}

We examined data from 23 hip joints of 21 patients with primary hip OA, which were classified into KellgrenLaurence (KL) grading I to IV [7]. Plain radiographs and MRI were performed on all of the 23 joints. In our institutions, we perform imaging assessment of OA using not only plain radiographs, but also MRI. Therefore, we in principle perform MRI on all of the patients with hip OA. Pain was assessed based on the pain scale of Denis [8]: P1, no pain; P2, occasional minimum pain with no need for medication; P3, moderate pain with occasional medication, 
but no interruption of work or significant changes in activities of daily living (ADL); P4, moderate to severe pain with frequent medication and occasional absence from work or significant change in ADL; P5, constant or severe incapacitating pain requiring chronic medication. A Welch $t$ test was performed for age, height, weight, body mass index (BMI), bone mineral density (BMD) (L1-4), BMD in affected-hip (A-Hip), and a Mann-Whitney $U$ test was performed for KL grading. The patients' data are shown in Tables 1-3.

We classified patients with hip OA at the time of MRI examination into the following groups: a group without pain or with a slight degree of pain (P0 or P1) who transitioned from a condition of joint pain (P3 or $\mathrm{P} 4)$ in the past in Table 1 (group A), and another group with a deteriorated joint pain (P3, P4, or P5) in Table 2 (group B).

We examined the relationship between joint pain and signal alterations detected by MRI in 23 hip joints in 21 patients with hip OA. All of the patients had KL grading IIV. Nineteen of 21 patients were female and 2 were male. Two patients who had bilateral hip OA were female; one patient was case 13 in group $A$, and another patient was case 12 in group A (case 4 in group B). In each group, the average age, height, body weight, BMI, and tendency-scores (T-scores) in the L1-4, the right hip, and the left hip were measured. Statistical analyses were performed using the statistical package $R$, version 2.10.1 (available at http://www.r-project.org) as shown in Table 3. A $P<0.05$ was considered to be statistically significant. Thirteen patients had already received osteoporosis treatment before hip MRI examination. MRI acquisition conditions were as follows: Coronal and sagittal views using T1-weighted imaging (TR: 530 (SI), FA: 90 (SI), TE: 14 (SI)) and short $\tau$ inversion recovery (STIR) T2-weighted imaging (T2-STIR) (TR: 5010 (SI), FA: 180 (SI), TE: 71 (SI), TI: 150 (SI)) were used for the hip skeletal survey. The strength of the magnetic field was $1.5 \mathrm{~T}(\mathrm{SI})$. The regions that had high signal changes by T2-STIR and low signal changes by T1-weighted imaging were evaluated by two independent board-certified orthopedic surgeons and one radiologist. All of the bone signal changes were judged to be observed only when the signal changes were detected by both T1-weighted imaging and T2-STIR. BMD was measured using a dual-energy Xray absorption (DXA) fan-beam bone densitometer (Lunar Prodigy; GE Healthcare, Waukesha, WI, USA) at the L1-4 levels of the posteroanterior spine and bilateral hip.

All of the patients had nonsteroidal anti-inflammatory drugs and/or tramadol when they had joint pain. All of the patients were generally in a good condition and did not have any serious complications previously. The current study was approved by our Institutional Ethics Committees and informed consent was obtained from all of the patients.

\section{RESULTS}

In group $\mathrm{A}$, the average age, height, body weight, and BMI in group A were 67.4 years, $153.3 \mathrm{~cm}, 52.9 \mathrm{~kg}$, and $22.5 \mathrm{~kg} / \mathrm{m}^{2}$, respectively. Average T-scores in the L1-4, the right hip, and the left hip were -1.3, -1.4, and -1.2, respectively. In group $\mathrm{B}$, the average age, height, body weight, and BMI were 70.5 years, $155.5 \mathrm{~cm}, 53.8 \mathrm{~kg}$, and $22.3 \mathrm{~kg} / \mathrm{m}^{2}$, respectively. Average T-scores in the L1-4, the right hip, and the left hip were $-0.6,-0.5$, and -1.3 , respectively. There was no statistically significant difference in age, height, weight, BMI, BMD, or KL grading between group $\mathrm{A}$ and group $\mathrm{B}$ as shown in Table $\mathbf{3}$.

There were 15 joints in 14 patients in group A as shown in Table 1. There was no broad signal change in any of the 15 joints in the hip MRI, although three joints had femoral and/or acetabular cysts (local signal changes). According to the pain scale of Denis, P3 was seen in one joint and P4 was seen in another 13 joints at the onset. At the time of MRI examination, P0 was seen in one joint and P1 was seen in another 14 joints [8].

There were 8 joints in 8 patients in group B as shown in Table 2. Of note, all of the patients had deteriorated and continuous joint pain (P3, or P4) [8] at the time of MRI. Severe joint pain was very recently seen in one joint of one patient. However, no signal change was observed in the hip MRI of this patient. In 3 joints with bone cysts, no broad signal change was seen. Four joints showed broad signal changes in the femoral head and acetabulum (One joint also had bone cyst). Joint pain showed repeated remission and deterioration (P3, P4, or P5) [8]. In addition, in 4 of 5 patients with joint pain and broad signal changes on MRI, hip joint pain was decreased thereafter.

There was no hip joint showing broad signal changes in Group A. By contrast, more than half of the hip joints showed broad signal changes in Group B.

\section{CASE PRESENTATION}

\section{Patient 1 (Case 1 in Group A)}

A 67-year-old woman, $153 \mathrm{~cm}$ tall, and weighing $54 \mathrm{~kg}$ visited our hospital. She had fallen and experienced bone fractures in her wrist before she visited our hospital. At her first visit, she complained of right hip joint pain (P4). Plain radiographs showed OA at KL grading III (Fig. 1). Since then, joint pain has shown repeated remission and deterioration. However, her pain has recently much decreased (P0). Recent plain radiographs also showed OA at KL grading III. Recent hip MRI showed no signal changes in right hip joints (Fig. 2a, b).

\section{Patient 2 (Case 3 in Group B)}

A 74-year-old woman, $152.0 \mathrm{~cm}$ tall and weighing 57.5 $\mathrm{kg}$ with no history of OA visited our hospital. At her first visit, she complained of right hip joint pain (P4). Plain radiographs showed OA at KL grading IV (Fig. 3). Since then, joint pain has shown repeated remission and deterioration. Recent plain radiographs also showed $\mathrm{OA}$ at KL grading IV. MRI was performed at the time of right hip joint pain (P4). MRI showed high signal change in the entire femoral head and acetabulum in T2-STIR (Fig. 4).

\section{Patient 3 (Case 12 in Group A and Case 4 in Group B)}

A 72-year-old woman, $155.0 \mathrm{~cm}$ tall and weighing 57.0 $\mathrm{kg}$ with no history of $\mathrm{OA}$ visited our hospital. Bilateral hip 
Table 1. The 15 Joints in 14 Patients without Pain or with a Slight Degree of Pain at Present as Shown in Group A. Statistically Analyzed Data for Age, Height, Weight, BMI, BMD (L1-4), BMD (L-Hip), BMD (R-Hip), BMD (A-Hip), and KL Grading in Group A

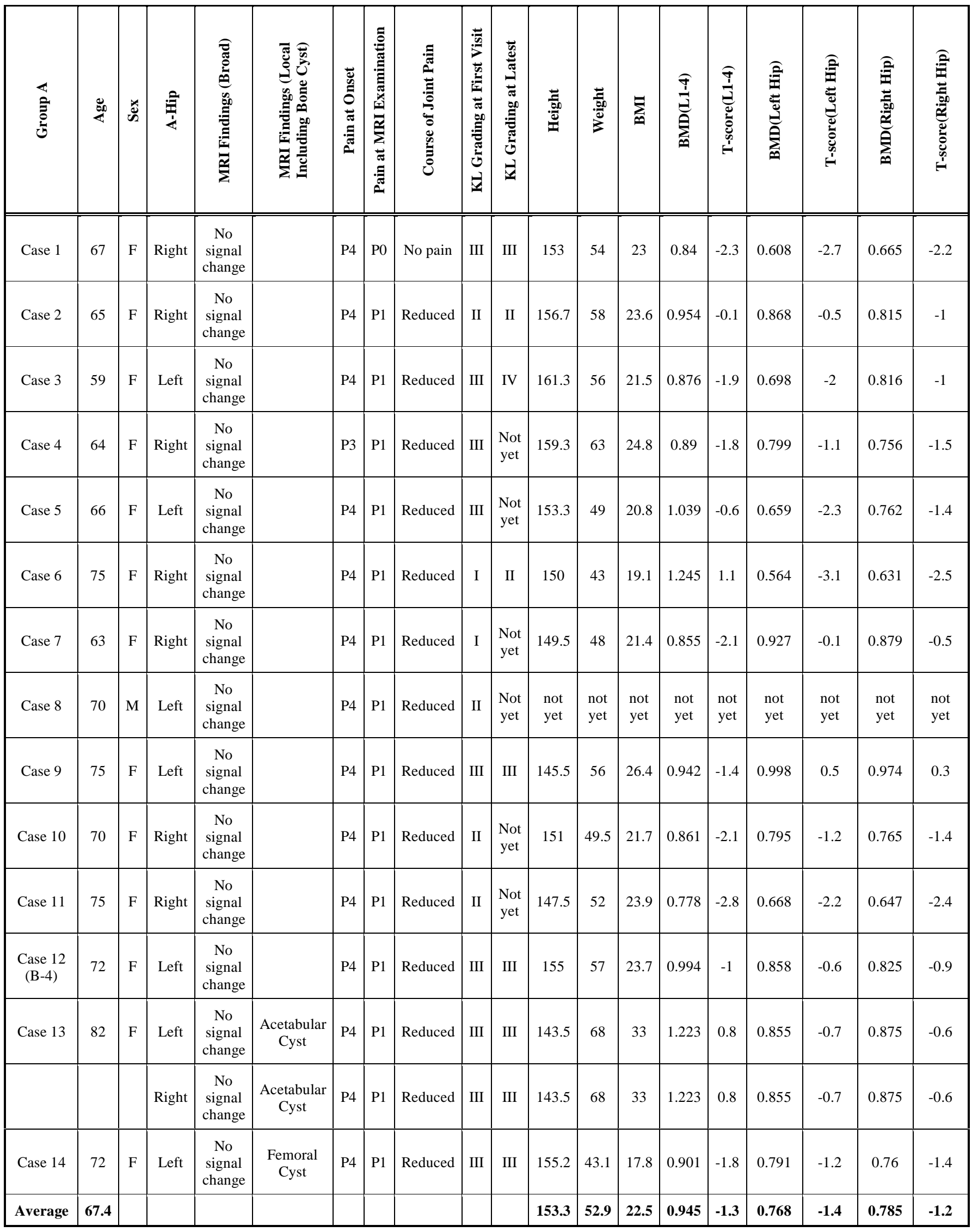


Table 2. The 8 Joints in 8 Patients with Deteriorated Joint Pain at Present as Shown in Group B. Statistically Analyzed Data for Age, Height, Weight, BMI, BMD (L1-4), BMD (L-Hip), BMD (R-Hip), BMD (A-Hip), and KL Grading in Group B

\begin{tabular}{|c|c|c|c|c|c|c|c|c|c|c|c|c|c|c|c|c|c|c|c|}
\hline ڤ̆ & $\underset{4}{4}$ & ڤ゙્ & 邹 & 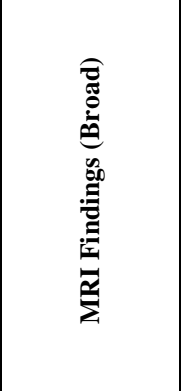 & 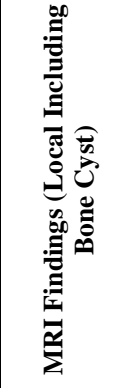 & 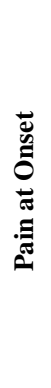 & 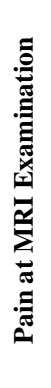 & 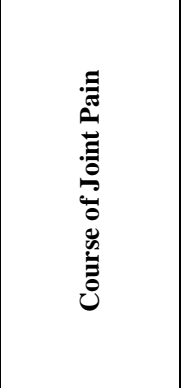 & 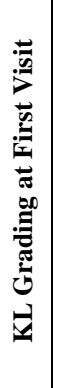 & 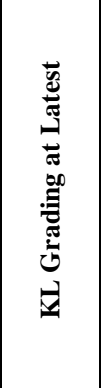 & te & 章 & $\sum_{\infty}$ & 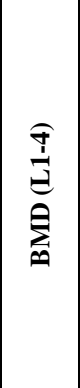 & 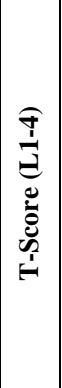 & 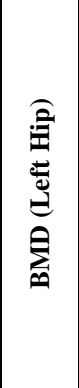 & 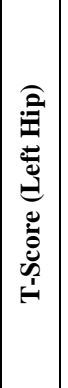 & 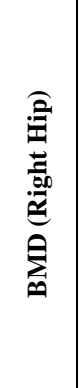 & 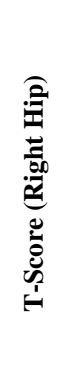 \\
\hline Case 1 & 68 & F & Left & $\begin{array}{l}\text { Broad femoral } \\
\text { and acetabular } \\
\text { signal changes }\end{array}$ & & P4 & P5 & Deteriorated & IV & IV & 157.7 & 56 & 22.5 & 1.179 & 0.6 & 0.98 & 0.4 & 0.667 & -2.2 \\
\hline Case 2 & 69 & $\mathrm{~F}$ & Left & $\begin{array}{l}\text { Broad femoral } \\
\text { and acetabular } \\
\text { signal changes }\end{array}$ & & P4 & P4 & Deteriorated & III & IV & 151 & 49.5 & 21.7 & 0.842 & -2.2 & 0.737 & -1.6 & 0.72 & -1.8 \\
\hline Case 3 & 74 & F & Right & $\begin{array}{l}\text { Broad femoral } \\
\text { and acetabular } \\
\text { signal changes }\end{array}$ & & P4 & P4 & Deteriorated & IV & IV & 152 & 57.5 & 24.8 & 1.096 & -0.2 & 0.909 & $\mid-0.2$ & 0.95 & 0.1 \\
\hline $\begin{array}{l}\text { Case } 4 \\
(\mathrm{~A}-12)\end{array}$ & 72 & $\mathrm{~F}$ & Right & $\begin{array}{l}\text { No signal } \\
\text { change }\end{array}$ & $\begin{array}{c}\text { Femoral } \\
\text { Cyst }\end{array}$ & P3 & P4 & Deteriorated & III & III & 155 & 57 & 23.7 & 0.994 & -1 & 0.858 & -0.6 & 0.825 & -0.9 \\
\hline Case 5 & 68 & $\mathrm{~F}$ & Right & $\begin{array}{l}\text { No signal } \\
\text { change }\end{array}$ & $\begin{array}{c}\text { Femoral } \\
\text { Cyst }\end{array}$ & P3 & P3 & Deteriorated & I & I & 149 & 48 & 21.6 & 1.032 & -0.7 & 0.737 & -1.6 & 0.758 & -1.5 \\
\hline Case 6 & 72 & M & Left & $\begin{array}{l}\text { No signal } \\
\text { change }\end{array}$ & $\begin{array}{c}\text { Acetabular } \\
\text { Cyst }\end{array}$ & P4 & P4 & Deteriorated & III & Not yet & 168 & 55 & 19.4 & 0.881 & -2.5 & 0.75 & -1.5 & 0.739 & -1.6 \\
\hline Case 7 & 62 & $\mathrm{~F}$ & Right & $\begin{array}{c}\text { Broad femoral } \\
\text { head signal } \\
\text { changes }\end{array}$ & $\begin{array}{c}\text { Femoral } \\
\text { Cyst }\end{array}$ & P4 & P4 & Deteriorated & IV & IV & 158 & 50 & 20 & 0.901 & -2 & 0.769 & $\mid-1.4$ & 0.748 & -1.6 \\
\hline Case 8 & 58 & $\mathrm{~F}$ & Left & $\begin{array}{l}\text { No signal } \\
\text { change }\end{array}$ & & P3 & P3 & $\begin{array}{c}\text { Pain } \\
\text { (very recently) }\end{array}$ & I & Not yet & 153.6 & 51 & 21.6 & 0.98 & -1.1 & 0.868 & -0.5 & 0.835 & -0.8 \\
\hline Average & 70.5 & & & & & & & & & & 155.5 & 53.8 & 22.3 & 1.039 & -0.6 & 0.875 & -1.5 & 0.779 & -1.3 \\
\hline
\end{tabular}

Table 3. Various Parameters were Statistically Analyzed. There was No Statistically Significant Difference in Age, Height, Weight, BMI, BMD, or KL Grading Between Group A and Group B

\begin{tabular}{|c|c|c|c|}
\hline & Group A & Group B & \multirow{2}{*}{ p-Value } \\
\cline { 2 - 4 } & Mean \pm Standard Error & Mean \pm Standard Error & 0.32 \\
\hline \hline Age & $70.5 \pm 1.7$ & $67.9 \pm 1.9$ & 0.16 \\
\hline Height & $151.7 \pm 1.5$ & $53.0 \pm 1.3$ & 0.52 \\
\hline Weight & $54.6 \pm 2.1$ & $21.9 \pm 0.6$ & 0.17 \\
\hline BMI & $23.8 \pm 1.2$ & $0.988 \pm 0.040$ & 0.79 \\
\hline BMD (L1-4) & $0.973 \pm 0.041$ & $0.827 \pm 0.034$ & 0.29 \\
\hline BMD (A-Hip) & $0.778 \pm 0.029$ & I:II:III:IV=2:0:3:3 & 0.33 \\
\hline KL grading at First Visit & I:II:III:IV=2:4:9:0 & \\
\hline
\end{tabular}

*Welch's t-test was performed for Age $\sim$ BMD.

Mann-Whitney's U test was performed for K-L classification.

*A-Hip is affected hip.

joint pain started about 5 years ago; since then, bilateral joint pain has improved and worsened repeatedly. She first visited our hospital about 6 months ago and complained of continuous right hip joint pain (P4). Her left hip joint pain has improved (P1). Plain radiographs showed bilateral hip OA of KL grading III (Fig. 5). MRI analysis showed no signal changes in the left hip joint, and bone cysts and local signal changes in her right femoral head (Fig. 6a, b). 


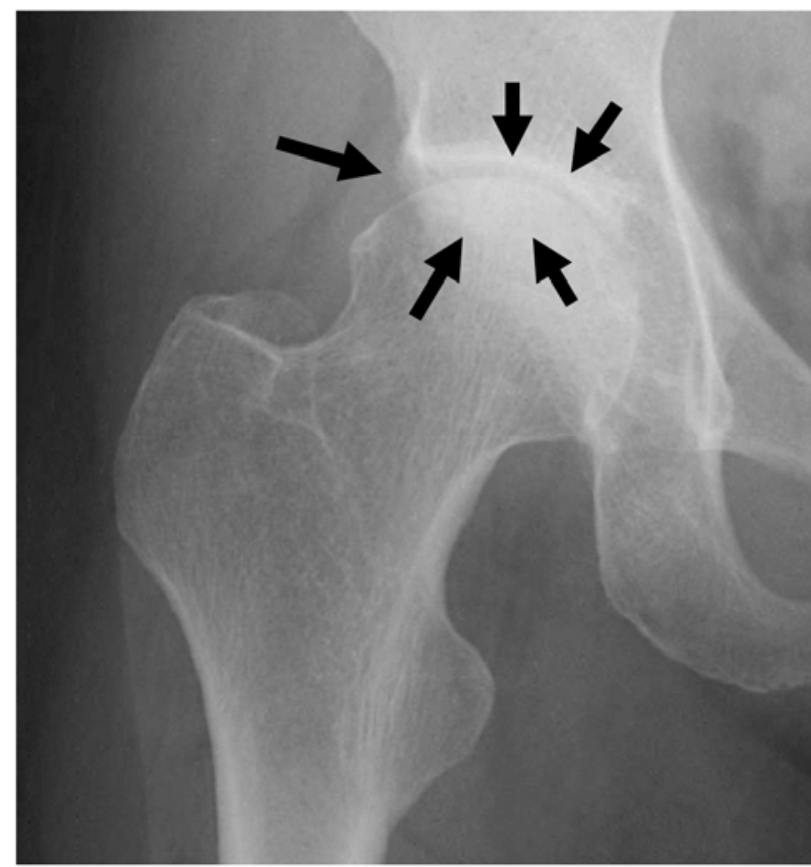

Fig. (1). A plain radiograph taken when the patient had severe right hip joint pain. The radiograph shows KL grading III right hip OA. Joint space narrowing, osteophytes, and osteosclerotic changes are seen in the right hip joint.

\section{DISCUSSION}

In this study, MRI showed that signal changes in bones were clearly detected in the OA patients with joint pain. By contrast, broad bone signal changes were not detectable if the patients did not show any pain. Based on our findings, we propose that bone signal changes detected by MRI could reflect hip OA progression in accordance with joint pain.
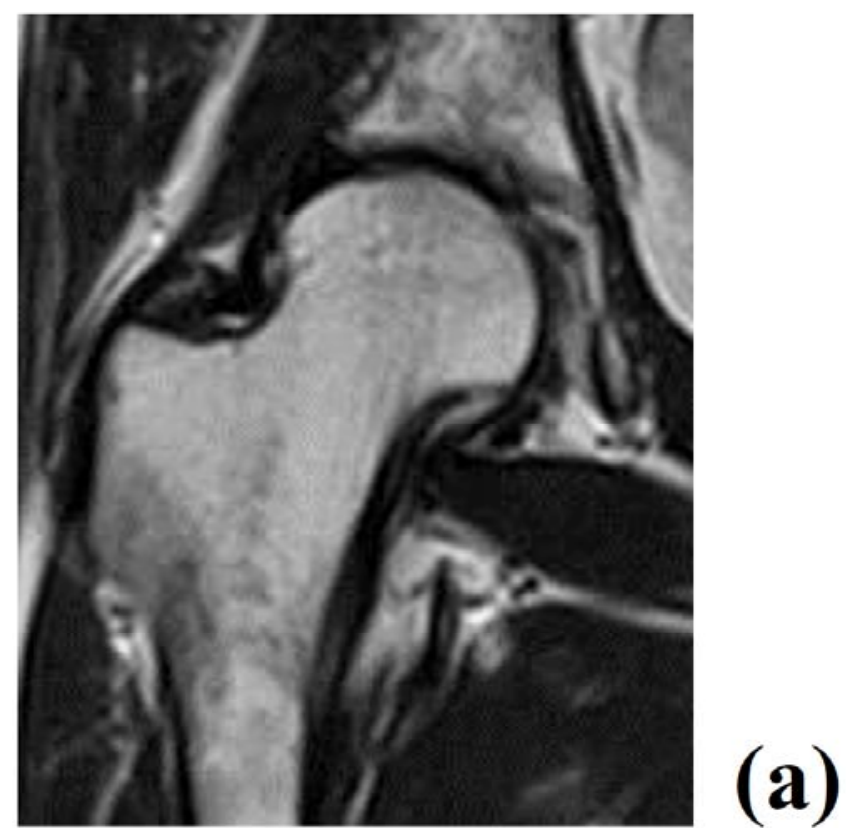

Usually, low intensity on T1-weighted imaging and high intensity on T2-weighted imaging implies bone marrow edema or hemorrhage, and these findings are not specific to bone fractures. We have previously reported MRI showing bone signal changes in osteoporotic patients with vertebral fracture or with bone metastasis $[9,10]$. In elderly patients with back pain, it is sometimes challenging to accurately diagnose bone fracture or bone metastasis in vertebrae [9]. Stafford et al. found diffusely reduced signal intensity in the bone marrow space on T1-weighted imaging and increased signal intensity on T2-weighted imaging in the area of stress fractures [11]. Yao and Lee found that occult or microfractures can be detected on T2-weighted imaging [12]. Karthiga et al. reported that MRI was helpful to identify bone marrow edema as a sign of recent fracture at the fracture site [13]. We demonstrated that a vertebral body with these MRI findings evolved into late collapse and/or sclerosis, and back pain was decreased and concluded that a low signal on T1-weighted imaging for the vertebral body with back pain indicated the presence of a fracture [10]. In this study, in most patients with joint pain and signal changes on MRI, hip joint pain was decreased thereafter. Guermazi et al. have recently reviewed that these MRI signal changes in joints frequently suggest microfractures [5]. Taken together, we speculate that bony alterations of the hip on MRI indicate microfracture or insufficiency fracture.

Recently, OA is considered to be a disease process of the entire joint that involves multiple tissues in and around the joint [5]. Our study revealed that hip OA patients without joint pain had no signal change, and most hip OA patients with joint pain had bone signal changes on MRI. Therefore, the hip joint pain might be caused by bone alterations in hip $\mathrm{OA}$ patients. In our previous report, we reviewed and summarized that bone abnormalities of the proximal femur might be one of the causes of primary hip OA and might proceed to further stages of OA [unpublished data]. These

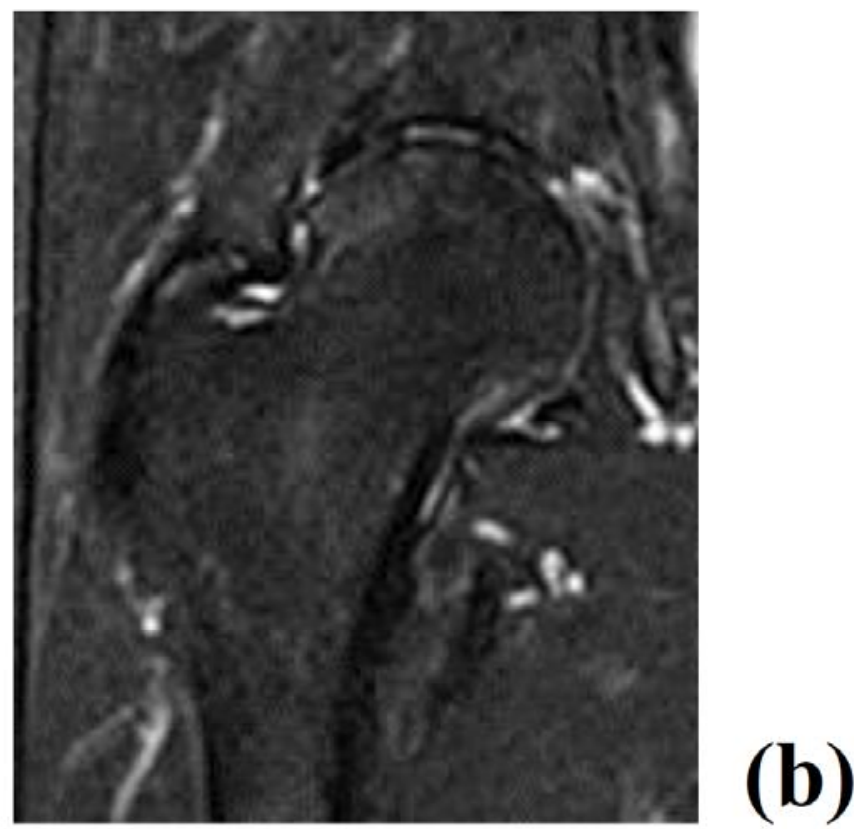

Fig. (2). MRI showing no signal changes in right hip joints. Note that there was almost no joint pain when MRI was performed. No signal change by T1-weighted image (a) and T2-STIR (b) was seen in the right hip joint. 
results suggest that the MRI signal changes could be a hallmark to observe OA progression.

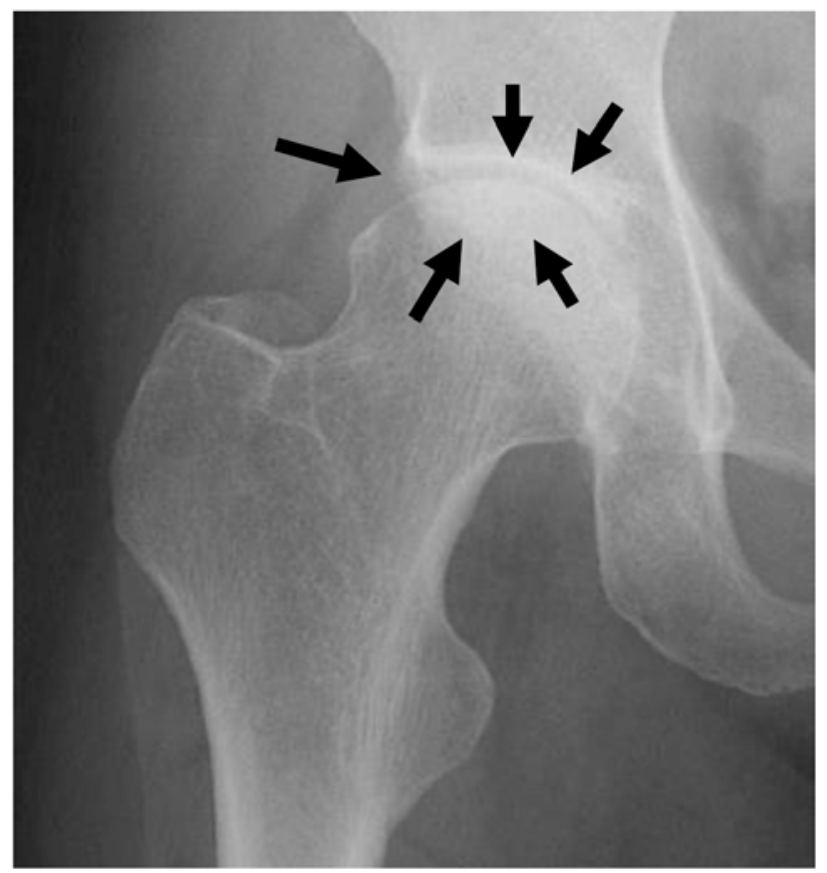

Fig. (3). A plain radiograph taken when the patient had severe right hip joint pain. Plain radiograph showing KL grading IV right hip OA. Joint space disappearance, osteophytes, and osteosclerotic changes (arrows) are seen in the right hip joint.

Bousson et al. interestingly report that osteosclerosis in OA occurs in parallel with joint space reduction using computed tomography (CT). They suggest that the mechanism might be new bone deposits or callus formation on the fracture trabeculae. The authors also report that $\mathrm{CT}$ is an elegant technique with which to assess and quantify the density of mineralized tissues, such as subchondral bone sclerosis and cysts [14]. Our findings are consistent with their data regarding bone alterations, such as insufficiency fractures, as detected by MRI and which might lead to OA. The authors focused on subchondral bone alterations using CT. However, we report in this study that MRI analyses revealed broad bone alterations in the femoral head in the hip OA patients with joint pain. Therefore, it is expected that broad signal changes, not only in subchondral bones, but other bone areas, might have been observed if MRI had been performed in the patients from Bousson's group.

Inui et al. recently indicated that bone cysts generally form in advanced OA. Various theories for the mechanism of their development have been proposed during the past seven decades [15]. Bone cysts associated with $\mathrm{OA}$ are considered to be formed during the mechanical processes in the focal areas of bone damage and necrosis $[15,16]$. However, the underlying mechanism remains unknown. As Goldring recently reviewed, bone cysts occur in patients with advanced OA [16]. However, Inui et al. report that dysplastic hips sometimes show cysts in pre or early-staged OA [15]. Goldring also proposes that one of the causes of bone cyst formation is in the process of repairing bone microfractures [16]. In our study, bone cysts were observed in the femoral head and in the acetabulum regardless of the presence of joint pain. In most cases, it was difficult to identify cysts only by plain radiograph. Based on previous reports and our findings, we speculate that bone cysts might occur from microdamage or microfractures of bones. We consider that the bone cysts can be more clearly identifiable at advancedstaged OA because the surrounding areas of cysts show osteosclerotic changes by plain radiograph.

In our previous study, we proposed that bone alterations in the hip joint might be one of the causes of primary hip OA. We also previously classified those patients into the following OA stages: (1) MRI-based signal change stage: having joint pain without or with early radiographic OA changes but with signal changes by MRI, (2) remissionstaged OA: having no or a slight degree of joint pain with radiographic OA but a slight degree of or no bone alterations
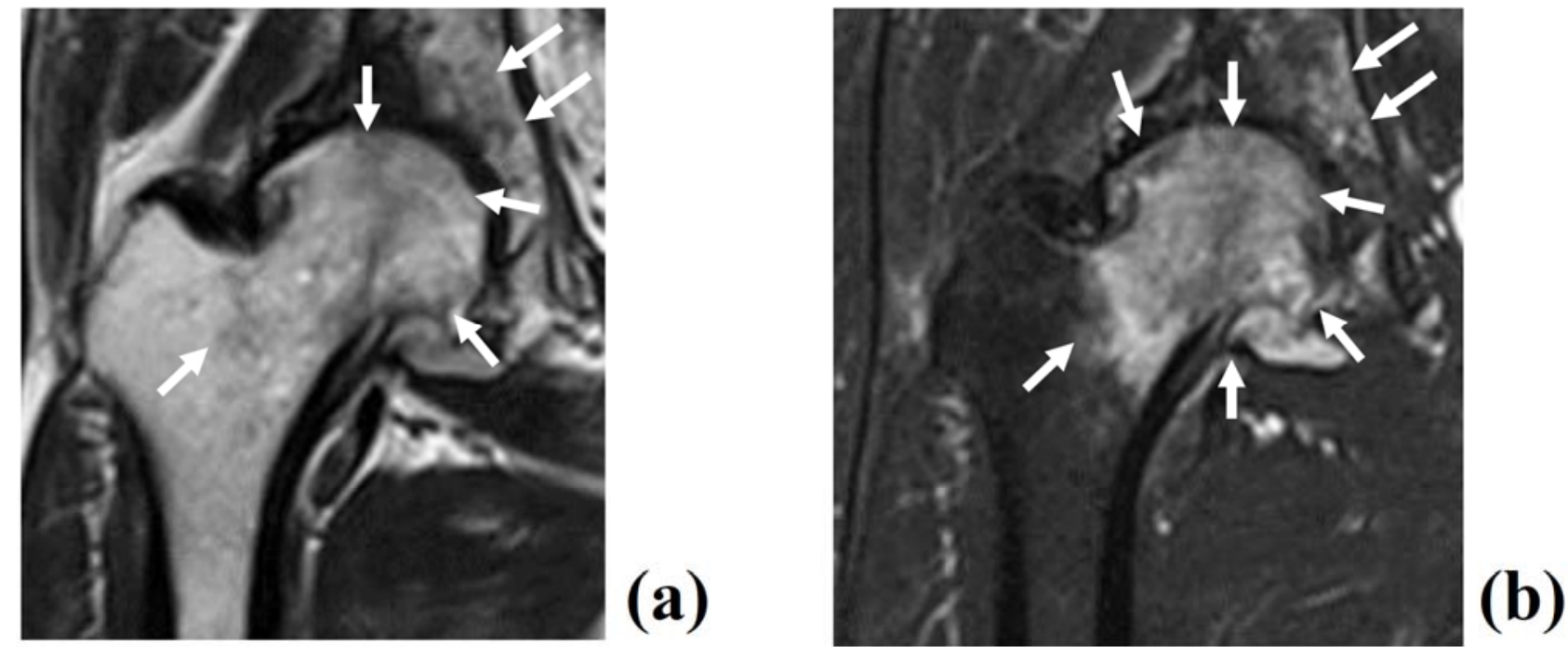

Fig. (4). MRI showing high signal change in the entire femoral head and acetabulum. Broad low intensity signal by T1-weighted image (a) and high intensity by T2-STIR (arrows) (b) in the right femoral head and acetabulum. Note that there was continuous joint pain when MRI was performed. 


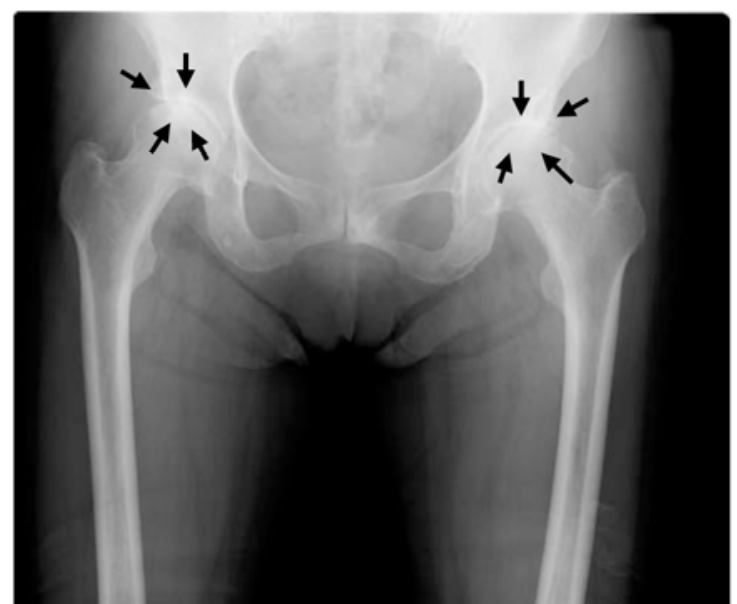

Fig. (5). A plain radiograph taken when the patient had bilateral hip joint pain. Plain radiograph showing KL grading III (right hip)/III (left hip). Joint space narrowing, osteophytes, and osteosclerotic changes are seen in the bilateral hip joint (arrows).

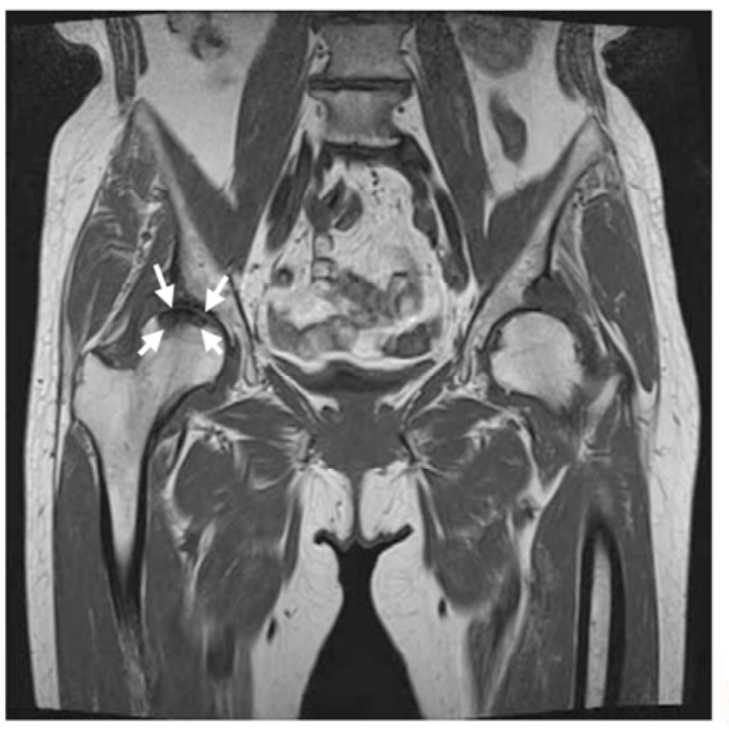

(a)

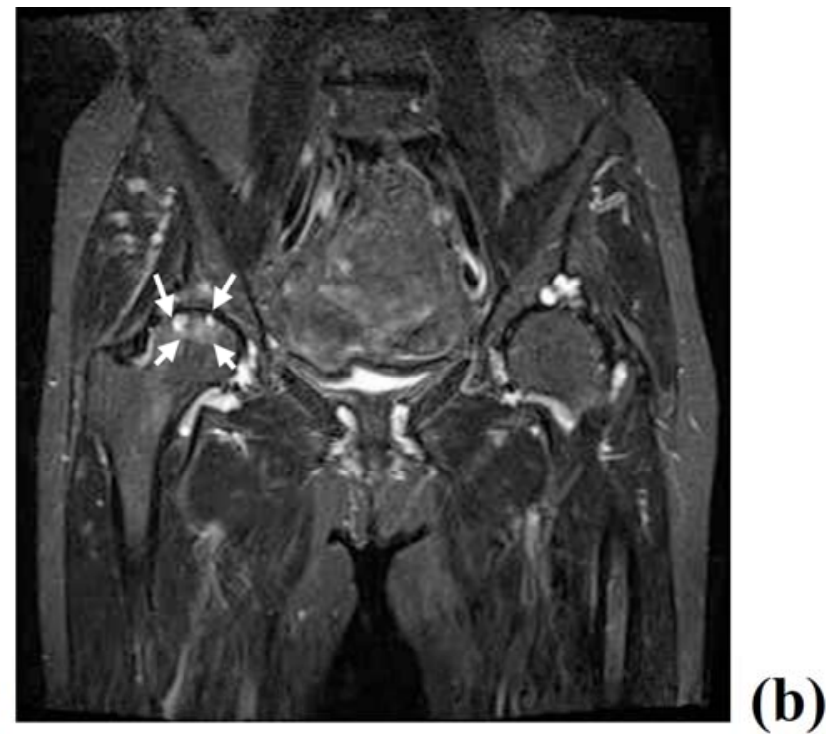

Fig. (6). MRI showing bone cysts and local signal changes in the load-bearing areas of the right femoral head, and no signal change in the left hip joint. Local low intensity in the femoral head by T1-weighted image (arrow) (a) and high intensity by T2-STIR (arrows) (b) in the right femoral head. by MRI, (3) end-staged OA: having joint pain with radiographic $\mathrm{OA}$ and significant bone alterations by MRI [unpublished data]. Collectively, we propose that the pathophysiology of OA could be repetitive bone alterations with cartilage degeneration, not just simple mechanical stresses onto joint tissues. In the current study, we consider that the cases in group A who have almost no joint pain correspond to remission-staged OA, the cases in group B with improved joint pain correspond to MRI-based signal change stage, and the cases in Group B with deteriorated joint pain correspond to end-staged OA.

Limitations of this study include that the number of patients studied was relatively small. Therefore, further studies with more patients are needed to confirm our findings.

In conclusion, hip OA patients without joint pain have no signal change, and most hip OA patients with joint pain have bone signal changes on MRI. The hip joint pain might be caused by bone alterations in hip OA patients. In addition, these bone signal changes of MRI might be a hallmark of cause and progression of OA.

\section{CONFLICT OF INTEREST}

The authors declare that they have no competing interests.

We thank Dr. Hiroshi Koshihara, a radiologist at Chusin Matsumoto Hospital for valuable help.

\section{ACKNOWLEDGEMENTS}

\section{REFERENCES}

[1] Moskowitz RW, Howell DS, Altman RD, Buckwalter JA Goldberg VM. Osteoarthritis. Diagnosis and Medical/Surgical Management. $3^{\text {rd }}$ ed. Philadelphia: W.B. Saunders 2003.

[2] Mahajan A, Verma S, Tandon V. Osteoarthritis. J Assoc Physicians India 2005; 53: 634-41.

[3] Radin EL, Rose RM. Role of subchondral bone in the initiation and progression of cartilage damage. Clin Orthop Relat Res 1986; 213 : 34-40.

[4] Burr DB, Gallant MA. Bone remodelling in osteoarthritis. Nat Rev Rheumatol 2012; 8: 665-73.

[5] Guermazi A, Roemer FW, Haugen IK, Crema MD, Hayashi D. MRI-based semiquantitative scoring of joint pathology in osteoarthritis. Nat Rev Rheumatol 2013; 9: 236-51.

[6] Roemer FW, Guermazi A. MR imaging-based semiquantitative assessment in osteoarthritis. Radiol Clin North Am 2009; 47: 63354.

[7] Muraki S, Oka H, Akune T, et al. Prevalence of radiographic knee osteoarthritis and its association with knee pain in the elderly of 
Japanese population-based cohorts: the ROAD study. Osteoarthr Cartil 2009; 17: 1137-43.

[8] Denis F, Armstrong GW, Searls K, Matta L. Acute thoracolumbar burst fractures in the absence of neurologic deficit. A comparison between operative and nonoperative treatment. Clin Orthop Relat Res. 1984; 189: 142-9.

[9] Yuzawa Y, Ebara S, Kamimura M, et al. Magnetic resonance and computed tomography-based scoring system for the differential diagnosis of vertebral fractures caused by osteoporosis and malignant tumors. J Orthop Sci 2005; 10: 345-52.

[10] Takahara K, Kamimura M, Nakagawa H, Hashidate H, Uchiyama $\mathrm{S}$. Radiographic evaluation of vertebral fractures in osteoporotic patients. J Clin Neurosci 2007; 14: 122-6.

[11] Stafford SA, Rosenthal DI, Gebhardt MC, Brady TJ, Scott JA. MRI in stress fracture. AJR Am J Roentgenol 1986; 147: 553-6.
[12] Yao L, Lee JK. Occult intraosseous fracture: detection with MR imaging. Radiology 1988; 167: 749-51.

[13] Karthiga S, Dubey S, Garber S, Watts R. Scurvy: MRI appearance. Rheumatology (Oxford). 2008; 47: 1109.

[14] Bousson V, Lowitz T, Laouisset L, Engelke K, Laredo JD Osteoporos Int 2012; 23 Suppl 8: S861-5.

[15] Inui A, Nakano S, Yoshioka S, et al. Subchondral cysts in dysplastic osteoarthritic hips communicate with the joint space: analysis using three-dimensional computed tomography. Eur J Orthop Surg Traumatol 2012 Sep 27. [Epub ahead of print].

[16] Goldring SR. Alterations in periarticular bone and cross talk between subchondral bone and articular cartilage in osteoarthritis. Ther Adv Musculoskelet Dis 2012; 4: 249-58.

(C) Kamimura et al.; Licensee Bentham Open.

This is an open access article licensed under the terms of the Creative Commons Attribution Non-Commercial License (http://creativecommons.org/licenses/by-nc/ $3.0 /$ ) which permits unrestricted, non-commercial use, distribution and reproduction in any medium, provided the work is properly cited. 